\title{
Vitamin B6 Deficiency
}

National Cancer Institute

\section{Source}

National Cancer Institute. Vitamin B6 Deficiency. NCI Thesaurus. Code C85221.

Deficiency of vitamin B6. It is usually caused by alcoholism, malabsorption, or as a side effect of medications. Signs and symptoms include stomatitis, glossitis, dermatitis, peripheral neuropathy, irritability, seizures, and anemia. 